\title{
Sindicalismo, SUS e planos de saúde
}

\author{
Trade unionism, Unified Health System \\ (SUS) and private health insurance
}

José Augusto Pina 1

Hermano A. Castro 1

Maria de Fátima A. Andreazzi 2

\footnotetext{
1 Centro de Estudos da Saúde do Trabalhador e Ecologia Humana, ENSP, Fiocruz.

Rua Leopoldo Bulhões, 1480, Manguinhos, 21041-210, Rio de Janeiro RJ. augusto@ensp.fiocruz.br 2 Núcleo de Estudos de Saúde Coletiva, UFRJ.
}

Abstract The article intends to discuss the patterns of interlocution between the Brazilian trade unionism, the public health system (SUS) and the private health insurance sector. Some thesis originated in the Public Health area about the subject are debated, in the light of more recent Social Science's studies concerned the Brazilian unionism. It presents a documentary analysis for the case of the largest National Workers Organization, named CUT. The need to discuss the problem in distinct political and economic conjunctures of the country is pointed out. The conflicts between the workers and the companies, added to the unemployment and deregulation of the labor markets, display the limits of private insurance markets in offering comprehensive health coverage and impel the workers representation to plead the state intervention in this market. The complexity of this dynamics gave impulse to the emergency of a syndicalism who is interested in the management of the complementary pension funds and private health plans. At the same time, the present conjuncture brings new possibilities to take the trade unionism back in the political arena, with the aim to agglutinate the interests of ample segments of the workers to pressure the State in the defense of the public health system improvement.

Key words Workers Health, Private Health Insurance, Health Policy, Trade unionism
Resumo Este artigo discute a interlocução do sindicalismo brasileiro com o Sistema Único de Saúde (SUS) e os planos e seguros privados de saúde. São ponderadas algumas teses na Saúde Coletiva à luz de estudos mais recentes nas Ciências Sociais sobre o sindicalismo e realizada análise documental para o caso da Central Única dos Trabalhadores (CUT), tomado aqui como referência. Aponta-se a necessidade de considerar os pesos relativos que a ação sindical atribuiu a cada um dos aspectos da relação, SUS e planos privados de saúde, pelas distintas conjunturas do país. O conflito entre trabalhadores e empresas somado ao desemprego e à precarização do trabalho expõe os limites das coberturas assistenciais privadas e impele a representação sindical a pleitear a intervenção estatal. O trabalho refletiu sobre as distintas modalidades de ação sindical na empresa e no Estado. A complexidade dessa dinâmica fez emergir um setor sindical interessado na gestão da previdência complementar e dos planos de saúde e, ao mesmo tempo, recria as circunstâncias e traz novas possibilidades de as organizações sindicais se colocarem na cena politica e aglutinar os interesses de amplos segmentos dos trabalhadores para pressionar o Estado na defesa da melhoria do sistema público de saúde.

Palavras-chave Saúde do trabalhador, Seguros privados de saúde, Politica de saúde, Sindicalismo 


\section{Introdução}

Este trabalho visa trazer elementos para discutir as práticas do sindicalismo brasileiro relativas à configuração e ao desenvolvimento do Sistema Único de Saúde (SUS) e do Setor Supletivo de Saúde, no que se refere à assistência à saúde do trabalhador.

No Brasil, os trabalhadores têm protagonizado importantes lutas em defesa dos direitos sociais, entre os quais o direito à saúde. As resoluções políticas das principais centrais sindicais consagram a defesa do sistema público de saúde1,2, posição assumida nos conselhos e fóruns de gestão de políticas públicas de saúde. Por outro lado, os principais sindicatos de trabalhadores incorporaram em suas negociações coletivas a demanda por melhoria da assistência médicohospitalar através de planos e seguros privados de saúde contratados pelas empresas.

Este quadro tem acompanhado, nas últimas décadas, a prática do movimento sindical, período em que, tanto o sistema de proteção social, em particular o sistema de saúde, quanto o próprio sindicalismo sofreram significativas alterações, expressão mais abrangente das transformações na formação social brasileira. Nos anos mais recentes, parece cristalizado o questionamento da capacidade dos trabalhadores - por serem consumidores de planos privados de saúde - e de suas organizações sindicais converterem-se em força social interessada em sustentar a melhoria e ampliação do SUS, apesar de considerados essenciais para seu fortalecimento 3 .

Pretendemos debater com algumas teses explicativas sobre esta problemática no campo da saúde coletiva/saúde do trabalhador e agregar o referencial das ciências sociais e humanas. A incorporação de alguns estudos sobre a trajetória recente do sindicalismo brasileiro desenvolvidos por autores da sociologia e da ciência política traz novas luzes sobre o problema. Será apresentado como esta questão tem sido considerada pelo sindicalismo, tomando como referência a Central Única dos Trabalhadores, a partir da análise documental, em especial, das resoluções de seus congressos e plenárias nacionais. Nossa opção pela CUT se justifica pelo fato de esta Central Sindical ter, em geral, em relação às demais: 1) uma trajetória de lutas relativamente contínua em defesa da saúde dos trabalhadores; 2) maior capacidade de organização e participação política e sindical; 3) hegemonia da representação político-sindical dos trabalhadores.
Nos limites deste artigo não serão exploradas as diferentes posições político-ideológicas no interior da CUT. Os documentos considerados não encerram a totalidade deste debate, mas possibilitam revelar uma determinada consciência em relação ao direito à saúde, possuidora de um considerável peso político no sindicalismo brasileiro.

\section{Saúde Coletiva: discutindo algumas teses explicativas}

A tese da universalização excludente 4 apontou na insatisfação com os serviços públicos, numa conjuntura dos anos 80 de contenção do gasto público, a razão para consolidar a expulsão do sistema público de saúde de segmentos sociais médios e de trabalhadores dos setores privado e público, mais dinâmicos da atividade produtiva. A expulsão dos trabalhadores politicamente mais organizados teria enfraquecido ainda mais a pressão social pela melhoria do setor estatal de saúde. Seguindo o mesmo raciocínio, Mendes 5 informa que, nos anos 90, o mecanismo de racionamento proporcionou a continuidade e a ampliação do processo de exclusão do sistema público para o setor supletivo de saúde, atingindo parte da classe média baixa e dos trabalhadores de pequenas empresas.

Contudo, em sua maioria, os trabalhadores com cobertura extra-SUS continuam a depender do setor público para resolver problemas de média e alta complexidade que não são total ou parcialmente cobertos pela atenção médica supletiva 5,6 . É este o caso, por exemplo, da venda de medicamentos pela Farmácia Popular, onde cerca de $65 \%$ de seus usuários são pacientes de convênios e particulares.

Assim, a inserção de tais segmentos nos planos de saúde não tem significado sua total saída do sistema público e, muito menos, deveria necessariamente explicar o afastamento do sindicalismo da efetiva mobilização pela melhoria do SUS.

Costa7 $^{7}$ sustenta que a opção das organizações sindicais pelos planos privados de saúde está na gênese da cultura associativa sindical brasileira. A presença de uma cultura da diferenciação entre os trabalhadores explicaria a grande mudança de oferta dos serviços médicos. Os valores e os anseios dos trabalhadores dos setores de ponta da economia por políticas diferenciadas de saúde implicariam a resistência destes à universalização. Além disso, a existência de com- 
petição entre as orientações ideológicas dos sindicatos (lideranças) e de sua base de trabalhadores (liderados) tem implicado a não conformidade entre as decisões em defesa do SUS assumidas pelas lideranças nas instâncias formais colegiadas e o conteúdo em prol dos planos de saúde das negociações dos liderados com as empresas e a setores produtivos particulares ${ }^{7}$.

Para Vianna ${ }^{8}$, não estaríamos diante de simples inconsistência entre representantes e representados, mas de um modelo de organização de interesses semelhante ao americano. Modelo que fomenta o lobbying como veículo de articulação dos interesses que tornam impossíveis politicas fundadas numa solidariedade abrangente. Segundo Vianna ${ }^{8}$, a retórica publicista das centrais sindicais e a estratégia particularista dos sindicatos a ela vinculados ocorreria porque o contexto no qual os lobbies são operados não espelha com exatidão a matriz americana. No Brasil, são muitos milhões que não têm acesso a tais formas de ação reivindicativa e que não podem ser descartados do discurso das centrais sindicais.

Devemos recordar que, nos anos 70, sindicatos de trabalhadores apresentaram inúmeros questionamentos ao convênio-empresa. Estes eram denunciados pela falta de isenção na prática da assistência médica subordinada ao empregador, pela queda da qualidade do tratamento, reduzido à prescrição de analgésicos e outros medicamentos, além de recusa para o tratamento de doenças que exigiam uma recuperação mais demorada9, 10, 11. Em 1981, o movimento sindical que se rearticulava na Conferência Nacional das Classes Trabalhadoras (Conclat) propunha a extinção dos convênios médicos, concomitantemente com a criação de uma rede base e pública de previdência12. Nas discussões em torno da reforma da assistência médica da Previdência Social, o Departamento Intersindical de Estudos e Pesquisas de Saúde e dos Ambientes de Trabalho (Diesat) identificou corretamente, já em 1982, que o processo de racionalização de serviços com controle de gastos [...] contraria os interesses de parte do empresariado hospitalar, não [...] para fortalecer o setor público, mas para concentrar a propriedade privada do setor, levando-a ao oligopólio e abrindo espaço para as multinacionais e capital financeiro que penetra fortemente na área de seguro-saúde ${ }^{13}$.

O movimento de reforma sanitária centraria o embate político-ideológico contra os prestadores de serviços de saúde do setor privado contratado pela Previdência Social em favor dos prestadores estatais ${ }^{14}$, polarização consagrada na 8 a Conferência Nacional de Saúde. Além disso, sua formulação acerca do financiamento necessário a uma universalização que preservasse os padrões de oferta alcançados pelos trabalhadores formais, à época, era dúbia. Se não negava a necessidade de recursos adicionais, priorizava a interpretação de que os recursos existentes eram mal-empregados e se esvaíam pelos canais da corrupção. Uma das principais justificativas para se empregar, de forma universalizada, os recursos da Previdência Social, era de que toda a sociedade contribuía indiretamente para ela e não apenas os trabalhadores e empresas contribuintes. O diagnóstico do Banco Mundial sobre a atenção à saúde no Brasil15 já apontava serem os trabalhadores formais privilegiados quando da utilização de recursos públicos, que deveriam, em função da eqüidade, ser desviados para os chamados pobres. Cremos que a falta, portanto, de uma política clara de repulsa a esse tipo de política poderia ter dificultado um engajamento mais ativo do movimento sindical, em uma reforma sanitária que dispensasse as coberturas privadas adicionais para atenção à saúde, já presentes em diversas categorias de trabalhadores.

Não deve ser desconsiderado o fato de que muitos sindicatos de trabalhadores qualificados e de segmentos médios participaram das ações nos Programas de Saúde do Trabalhador (PST) e nos Centros de Referência em Saúde do Trabalhador (CRST)16, 17, 18, inclusive com a experiência de gestão sindical 18 . E ainda a participação na 1ạ, 2a e 3a Conferência Nacional de Saúde do Trabalhador, respectivamente, em 1986, 1994 e 2005, as duas últimas realizadas em conjunturas significativamente distintas da primeira. Os PSTs e CRSTs têm possibilitado tornar públicos os dados referentes aos acidentes e doenças relacionadas ao trabalho em contraposição à ocultação dos danos à saúde dos trabalhadores praticada pelas empresas com a cumplicidade das empresas de medicina de grupo por elas contratadas ${ }^{19}$. Todavia, não ocorreu um massivo e qualitativo envolvimento de categorias expressivas de trabalhadores 17 . O movimento sindical no período pós-Constituição privilegiou uma atuação mais institucional, concentrando atenção nos fóruns nacionais de saúde (entre outros), mas se distanciando das ações nos PSTs e CRSTs20, estas marcadas pela descontinuidade 21 .

A temática por nós apresentada tem merecido pouca atenção da área de Saúde do Traba- 
lhador. Em trabalho de grande amplitude, Lacaz ${ }^{16}$, de forma bem concisa, registra tal prática sindical como paradoxal e contraditória. Posteriormente, o autor ${ }^{22}$, de forma sumária, assinalaria que o problema seria: a) a mudança de orientação em relação à assumida, no final dos anos 70, ao passar de uma posição de confronto com o capital para, na década de 1990, uma ação que implique certa conciliação; b) o resultado das transformações da formação sociocultural e dos hábitos de consumo das novas gerações de trabalhadores; e c) a falta ou a incipiente organização nos locais de trabalho.

No entanto, podemos apontar que a falta (ou a presença) de organização nos locais de trabalho não seria um indicativo relevante para explicar tal prática sindical, ainda mais se consideramos que os trabalhadores detentores de um elevado nível de organização no interior das empresas, como os da indústria automobilística, há mais de duas décadas, incorporaram em sua ação sindical a reivindicação por melhorias nos convênios médicos.

Ao discutir as relações entre oferta, demanda e necessidade em saúde sob a perspectiva marxista da reprodução social, Andreazzi23 nos informa que, para invocar a mudança de hábitos de consumo das novas gerações de trabalhadores, como explicação da política sindical em relação à atenção médica, seria necessário analisar as distintas conjunturas das últimas décadas, tendo a compreensão de que há de existir uma oferta que se aproveite das representações indistintas dos trabalhadores sobre suas necessidades de saúde para criar necessidades sociais de consumos, hábitos segundo os interesses dos ofertantes. Mas não somente. É preciso forjar a ação em direção a tal consumo, o que envolve processos coletivos em que as distintas classes e frações de classes sociais envolvidas, com os seus interesses materiais concretos e suas ideologias, disputam a consciência dos trabalhadores. $\mathrm{O}$ sindicalismo configura e expressa uma das formas dessa luta de classes.

Vimos que $\operatorname{Costa}^{7}$ condiciona a ação sindical por atenção à saúde pelas escolhas e preferências individuais dos trabalhadores. Mas, no que se refere à seguridade social no Brasil, tanto ele quanto Vianna ${ }^{8}$ privilegiam as articulações das organizações de interesses dos trabalhadores com os arranjos institucionais e as estruturas de decisão (acordos, mecanismos de concertação) do Estado. Nesta perspectiva, conceitualmente apoiada na abordagem institucionalista, o Estado é considerado um ator, despo- jado das formas de dominação fundadas nas relações sociais de produção, diante do qual o sindicalismo, um outro ator, se apresentaria para participar na formulação da política pública de saúde (entre outras). A evolução institucional do Estado e a organização sindical dos trabalhadores não são consideradas em relação à totalidade e à especificidade da estrutura social capitalista no Brasil em seu desenvolvimento histórico concreto, mas referidos à produção das políticas sociais, no limite, comparadas a modelos de proteção social e de cidadania próprios do Welfare State 24 . Com base neste referencial, identificaram o processo de expansão do mercado de planos de saúde no País como decorrente das demandas sociais dos trabalhadores e de seus sindicatos que emergiram das negociações coletivas nos anos 80 .

\section{Demandas sindicais por bem-estar na relação com a empresa e o Estado}

Tanto a formulação apoiada na cultura de diferenciação entre os trabalhadores, quanto a que considera a impossibilidade das organizações sindicais sustentarem políticas solidárias amplas apóiam-se numa evidência empírica. Nos anos 80 , expandiu-se a pauta de reivindicações por serviços sociais e de bem-estar negociados entre sindicatos e empresas, fato invocado para afirmar que, já naquele momento, o sindicalismo trocara o Estado pela empresa na definição de direitos sociais.

No entanto, o crescimento da ação sindical nas empresas não necessariamente configura afastamento das demandas dirigidas ao Estado. Isto depende da situação concreta e da conjuntura em que tais lutas se processam. Ao longo da década de 1980, o sindicalismo assumiu uma ação voltada para a aglutinação de forças numa mesma categoria profissional ou entre categorias distintas, valendo-se da mobilização para chegar à negociação 25, 26. As conquistas de uma categoria passavam a integrar a pauta geral de reivindicações do movimento sindical no Estado e, grande parte delas, foram consagradas na Constituição Federal de 1988 e/ou na legislação como direito de todos os trabalhadores, como é o caso da estabilidade para o trabalhador acidentado. As demandas por bem-estar às empresas, naquele momento, parecem ter contribuído para ampliar a pressão ao Estado no sentido de consagrar determinadas conquistas no rol de direitos sociais. 
Já nos anos 90, o quadro é outro e a tendência tem se dirigido em sentido contrário. As negociações coletivas têm se caracterizado por sua natureza particularista e descentralizada, reforçada pela iniciativa do governo federal em introduzir temas cuja negociação restringe-se ao âmbito das empresas, como a participação nos lucros e resultados e sobre flexibilização da jornada de trabalho, processo que se intensifica a partir da segunda metade da década de 1990. Parcela considerável dos sindicatos da CUT assumiram a diversidade entre setores e empresas como critério determinante para a negociação ${ }^{26}$. Manifesta-se, assim, um corporativismo não mais por referência ao Estado, mas um certo insulamento de grupo em torno de si mesmo, priorizando suas demandas salariais e sociais em negociação direta, setorial ou com cada empresa separadamente, isolando-se ou se contrapondo não de um suposto interesse geral da sociedade, mas da luta reivindicativa e política mais ampla em torno de uma plataforma comum dos trabalhadores 25 .

Em 1989, pesquisa realizada no segmento empresarial, citada por Mendes ${ }^{14}$, indicou que a pressão sindical não possuía peso importante entre os motivos apontados para justificar a adesão das empresas ao setor supletivo de saúde, fato também revelado por Checchia ${ }^{27}$. As principais razões estavam relacionadas às formas de controle sobre a força de trabalho ocupada: redução do absenteísmo, fixação do trabalhador no processo de trabalho, as funções político-ideológicas de identificação do trabalhador com a empresa $9,10,11,27$, e as novas modalidades de sua utilização e gestão ${ }^{28}$, na conjuntura aberta a partir da década de 1980, período de ascensão das lutas dos trabalhadores, entre as quais a luta pelo direito à saúde.

A negociação sindical se inclui como um dos aspectos considerados pelas grandes corporações industriais, financeiras e de serviços. Mas conforme Fernandes 28 , não existe uma relação de causalidade entre as demandas sindicais por serviços sociais, entre elas a de atenção médico-hospitalar, e a expansão da oferta destes serviços pelas empresas empregadoras. Este movimento só se generalizou como uma forma particular de proteção social, por meio da política estatal ao naturalizá-lo e incorporá-lo ao sistema de proteção social vigente ${ }^{28}$. As determinações do processo de expansão do mercado de planos e seguros de saúde nos remetem ao convênio-empresa, anos 60-70, com financiamento público, via seguro social, apoiado no interesse do empresariado em assegurar a produtividade do trabalho, num momento de intensificação da industrialização no país com grande impacto sobre a saúde dos trabalhadores. Na década de 1980, prossegue a expansão do setor supletivo de saúde caracterizado por formas autônomas de financiamento da assistência médica em relação ao setor público ${ }^{29}$ apesar de mantido mecanismo de renúncia fiscal aos usuários e empresas que contratam planos de saúde - apoiado na entrada do capital financeiro ${ }^{10}$.

A introdução de tecnologias e processos de gestão flexíveis com novos requisitos em termos de habilidades e valores para a força de trabalho constituiria um núcleo de novos operários e trabalhadores diretamente contratados que, conforme Alves ${ }^{30}$, apesar de sua redução numérica tendeu, nos anos 90, a aumentar o seu tempo médio de permanência nas empresas, executando com maior intensidade uma grande quantidade de operações.

O novo complexo de reestruturação produtiva, além de recrudescer a superexploração da força de trabalho ${ }^{30}$, pode ter acentuado a enorme diferenciação quanto ao acesso e aos padrões de qualidade dos serviços médico-hospitalares fornecidos pelas empresas aos trabalhadores. Conforme Santos ${ }^{31}$, essa diferenciação nas grandes empresas e sua rede de contratadas pode ser definida pela categoria profissional (qualificação, hierarquia funcional) ou pelo contrato de trabalho (vínculo direto, terceirizados, estagiários). O benefício do plano de saúde pode ser restrito aos funcionários da empresa ou, até, extensivo a esposas, dependentes e agregados. A rede credenciada pode ser composta desde os estabelecimentos considerados top de linha até o campo oposto; o padrão e a amplitude da cobertura do plano de saúde e sua gama de serviços podem variar de bem ampla até residual. Em outro trabalho, Santos 32 indica que a realidade do dia-a-dia dos trabalhadores do mercado formal, onde a insalubridade, a periculosidade e o tempo limite de afastamento para adoecidos ou acidentados determina um constante questionamento de seu estado de saúde, coloca em xeque a idealização de que os trabalhadores sejam uma elite do país por [...] terem, na maior parte, plano ou seguro privado de assistência à saúde ${ }^{32}$. Além disso, em grande parte, são os próprios trabalhadores que respondem, total ou parcialmente, por seus custos.

Como vimos, as demandas sindicais dos trabalhadores, até mesmo por assistência à saú- 
de, assumiram qualidades distintas nas diferentes conjunturas históricas. Apesar de constar nos acordos coletivos, a forte expansão da oferta de atenção médica supletiva não pode ser atribuída à pressão sindical dos trabalhadores. Outra questão se refere à desigualdade no acesso e na qualidade dos serviços de saúde no próprio setor supletivo - que não está isento das clivagens de classes sociais no país - recrudescida pelo processo de reestruturação produtiva. Este quadro nos conduz a recusar a oposição reducionista entre usuários do sistema supletivo versus usuários do SUS, o que torna ainda mais complexa as análises sobre a participação sindical na luta em defesa da saúde dos trabalhadores ${ }^{33}$.

\section{O SUS e os planos privados de saúde nas resoluções da CUT em tempos de política neoliberal}

Uma certa simplificação das contradições sociais ganhou amplitude no campo políticoideológico com a implementação das políticas econômicas e sociais restritivas de cunho neoliberal, no momento de implantação do SUS. Segundo Andreazzi ${ }^{34}$, adquiriu relevo - sob o discurso da universalização e da eqüidade nos termos do Banco Mundial - a argumentação de que a utilização do sistema público de saúde por categorias de maior renda tira o lugar dos mais pobres ${ }^{34}$. A Secretaria de Política Econômica do Ministério da Fazenda apontou como principal problema das políticas sociais no Brasil o privilégio concedido pelo atual sistema... a grupos de renda mais alta 35 .

O combate aos direitos sociais, genericamente estigmatizados como privilégios, tem assumido um dos aspectos centrais no discurso neoliberal e alcançado, segundo Boito Jr. ${ }^{25}$, uma hegemonia regressiva. Para o autor, as classes dominantes obtiveram uma hegemonia, ainda que de modo superficial, instável, precária, e com impacto desigual sobre os diferentes setores dos trabalhadores. Hegemonia conquistada sem concessões econômicas e, ao contrário, retirando e restringindo direitos das classes dominadas, neste sentido seu caráter regressivo. No Brasil, historicamente, o acesso restrito e segmentado aos direitos sociais gerou contradições no interior das classes trabalhadoras da cidade e do campo. Ao longo do tempo, suscitaram nos trabalhadores preteridos pelos direitos sociais uma revolta difusa, vocalizada na ce- na política pela ideologia neoliberal e negligenciada pelo sindicalismo 25 .

O movimento sindical foi atingido pela implantação da política neoliberal, que não poupou nem mesmo os setores de melhor organização (metalúrgicos do $\mathrm{ABC}$, bancários, petroleiros e servidores públicos). Os trabalhadores não ficaram passivos e empreenderam resistências diferenciadas, como a greve dos petroleiros de 1995, as ocupações dos trabalhadores rurais sem-terra e a constituição de movimentos sociais e de trabalhadores vitimados por acidentes e doenças do trabalho, com atuação internacional, como redes em contraposição aos grupos hegemônicos ${ }^{36,37}$. Todavia, a trajetória da CUT tem sido marcada por ambigüidades. Promoveu manifestações contrárias à privatização das empresas estatais e à flexibilização dos direitos trabalhistas, mas assimilou, em parte, propostas restritivas aos direitos dos trabalhadores, como no caso da reforma da previdência social e dos acordos para implantação de banco de horas 38 .

No que se refere às políticas públicas de saúde e educação, o 5o Concut ${ }^{1}$, em 1994, registrou a política contraditória da Central na defesa dos direitos sociais e afirmou a necessidade de lutar com o poder público por sua garantia para o conjunto dos trabalhadores. $\mathrm{O}$ 6o Concut ${ }^{39}$ firmou o compromisso de rever a tendência histórica dos sindicatos optarem por convênios médicos privados em processos negociais. Contudo, após este encontro na 9a e 10a Plenária Nacional 1 , assim como no 7o e $8 \underline{\text { o Congresso }}$ Nacional da CUT1', nenhum balanço foi apresentado a este respeito, nem sequer constariam das resoluções referências à política contraditória na luta pelos direitos sociais. Reitera-se, de forma genérica, o apoio à universalização, eqüidade, integralidade, descentralização e controle social no SUS.

Em 2003, o 8o Concut ${ }^{1}$ registra uma certa indefinição sobre a implantação da Rede Nacional de Atenção Integral à Saúde do Trabalhador no SUS. Neste mesmo ano, no Fórum de Saúde Suplementar promovido pela Agência Nacional de Saúde Suplementar (ANS), a representação da CUT40, 41 postulou que a ANS enfrente os problemas dos altos reajustes dos planos; de descredenciamento e insuficiência da rede pelas operadoras, restrições de acesso a serviços de média e alta tecnologia; a garantia de cobertura integral a todas as doenças. Propôs ainda o atendimento pelos planos ao trabalhador acidentado, mas sem mencionar suas 
limitações... nas ações de prevenção e intervenção no ambiente de trabalho 39 e de controladora e recolocadora imediata do trabalhador na produção/serviço 42 .

Apesar das ressalvas, o pleito sindical à ANS expressa o recrudescimento, a partir da segunda metade dos anos 90, de conflitos sindicais em torno das chamadas cláusulas sociais. Pina 43 registra que os metalúrgicos do Estado de São Paulo vinculados à CUT resistiram a forte pressão empresarial e mantiveram em suas convenções coletivas a estabilidade no emprego, até aposentadoria para o trabalhador acidentado ou com doença do trabalho. Nos últimos cinco anos, por meio de ação judicial impetrada pelo Sindicato dos Metalúrgicos do $\mathrm{ABC}, 231$ metalúrgicos com doenças relacionadas ao trabalho foram reintegrados às empresas após serem demitidos arbitrariamente. Além disso, somente em uma empresa na região do ABC/SP, 48 trabalhadores foram excluídos do plano de saúde porque estavam afastados por acidentes ou doenças do trabalho ${ }^{43}$. Este contexto agrega elementos para seguir questionando a aludida segurança da proteção à saúde dos planos 44

$\mathrm{O}$ acelerado crescimento da informalidade e da precarização nas relações de trabalho, do desemprego e a redução dos rendimentos reais dos trabalhadores 45 imporia aumentar a pressão sobre o SUS. Por um lado, porque reforça a tendência do sistema público como única alternativa para a maioria dos trabalhadores. Por outro, pela possibilidade de canalizar em favor do SUS os descontentamentos do operariado qualificado, dos assalariados e de setores médios pressionados pela queda de seus rendimentos e pelo aumento nos custos e demais conflitos com os planos de saúde. A iniciativa do Instituto Brasileiro de Defesa do Consumidor (Idec) 46 de São Paulo em editar uma cartilha apontando o SUS como o melhor Plano de Saúde pode indicar a presença desta possibilidade.

Este processo encontrou o sindicalismo, majoritariamente, debilitado política e ideologicamente. A CUT, no inicio da década de 1990, produziu uma inflexão em sua ação sindical, elevou o Contrato Coletivo de Trabalho à posição de principal definidor de suas demandas trabalhistas e sociais, deslocando o Estado para posição secundária. Em relação ao Estado, a CUT privilegiou uma atuação institucional para influir nas políticas públicas. Este seria um primeiro deslocamento, advertindo que a CUT rebaixou a posição do Estado, mas não o ex- cluiu, mesmo nos seus processos de pressão política em favor de direitos sociais. Mais recentemente um segundo deslocamento vem se processando, uma redefinição da posição sindical acerca do papel do Estado nas políticas sociais. O 6 o Concut ${ }^{39}$ explicitou e legitimou uma modalidade de ação já em curso na Central: Acostumamos a enxergar... Estado e mercado... como únicas alternativas de viabilização do bem-estar social. No entanto, a dinâmica atual tem-nos mostrado que outros atores sociais podem e devem contribuir nas definições, implementações, controle e eficácia das políticas públicas ${ }^{39}$.

A CUT - e várias entidades sindicais - em parceria com ONGs, os outros atores sociais, atuaria não apenas propondo políticas públicas, mas executando serviços sociais preteridos pelo Estado. Emergia um setor sindical empenhado na execução e gestão de projetos sociais recorrendo à disputa pelos fundos públicos, além de estimular a formação de Cooperativas de Seguros Civis, Cooperativas de fundo de pensão complementares sob argumentação de investir os recursos daí provenientes em experiências cooperativas e de autogestão para geração de emprego e renda no combate à precarização do trabalho ${ }^{39}$. Este sindicalismo explora os interstícios deixados pelo Estado para oferecer assistência aos trabalhadores e filiados sindicais. Caso sobrevalorizado, apontaria para um aumento das ações de assistência social em detrimento da mobilização e da luta por direitos 47 .

Então, estariam vedadas para o sindicalismo brasileiro as possibilidades de organizar ações reivindicativas de natureza social e política ampla e solidária? A complexidade desse processo não permite uma afirmação tão peremptória. A este respeito, concordamos com Stotz ${ }^{48}$ : se na sociedade a única previsão realista é a da luta, as circunstâncias sempre podem favorecer a emergência de lutas mais amplas, dependendo, em boa medida, da capacidade das lideranças saberem aproveitar as circunstâncias.

\section{Considerações finais}

Como foi apresentado, existem elementos suficientes para não considerar satisfatórias as interpretações presentes na Saúde Coletiva, discutidas no início deste artigo, acerca da interlocução do sindicalismo com o SUS e os planos privados de saúde. Alguns destes estudos têm responsabilizado, em diferentes graus e níveis, importantes segmentos de trabalhadores e suas 
organizações sindicais pela expansão da medicina suplementar e pela resistência ao SUS7, 8 . Ao discutir esta afirmação, consideramos que estes trabalhos não se ocuparam e, por isto, não analisaram os pesos relativos que a ação sindical atribuiu a cada um dos aspectos, SUS e planos privados de saúde, com respeito à singularidade histórica dos distintos momentos da conjuntura brasileira. Na década de 1980, predominou uma ação sindical mais ativa na defesa do sistema público, enquanto a negociação pela melhoria do plano privado de saúde assumia uma dimensão reativa. A partir do inicio da década de 1990, a posição da CUT diante das políticas neoliberais tem sido marcada por contradições e ambigüidades em relação aos direitos sociais. Nos últimos anos, emergiu um setor sindical que estabelece vínculos ideológicos com os planos de saúde e a previdência complementar.

A tendência seria a continuidade do público e do privado nas demandas sindicais por assistência à saúde dirigida ao Estado e às empresas. Diferentes posições convivem no meio sindical, muitas de forma contraditória, mas nem sempre antagônicas entre si. No âmbito da CUT identificamos três modalidades distintas de ação relativa à proteção social do Estado, a saber: a) pressionar o Estado para manter e ampliar os direitos sociais; b) participar institucionalmente na formulação de políticas públi- cas; e) disputar o fundo público para gerir e executar serviços sociais.

Levantamos uma diversidade de aspectos e considerações que necessitam de maior aprofundamento. Entre os quais, analisar os padrões de consumo de serviços de saúde e previdência da nova geração de trabalhadores da indústria e serviços que emergiram com maior dinamismo na economia. Em estreita relação, investigar a possibilidade de se acomodar na estrutura sindical brasileira um assistencialismo de novo tipo interessado na gestão da previdência complementar, de planos de saúde e do Seguro Acidente de Trabalho (SAT) para oferecer estes serviços aos trabalhadores e filiados sindicais.

Entendemos que a desigualdade na estrutura social brasileira e o crescimento dos limites da cobertura assistencial privada estão a oferecer as circunstâncias que recriam novas possibilidades de as organizações sindicais se colocarem na cena política. A depender da orientação que assumirem, as entidades sindicais estarão em maior ou menor condição para aglutinar os interesses de amplos segmentos dos trabalhadores e pressionar o Estado para ampliar e melhorar o sistema público de saúde e demais serviços sociais. Provavelmente, o percurso nesta direção será sinuoso, não compreenderá uma ação político-sindical única e, muito provavelmente, necessitará competir e superar posições antagônicas.

\section{Colaboradores}

JA Pina, HA Castro e MFS Andreazzi participaram igualmente de todas as etapas de elaboração do artigo.

\section{Agradecimento}

Agradecemos a Eduardo Navarro Stotz, pesquisador da Escola Nacional de Saúde Pública Sérgio Arouca - Ensp/ Fiocruz, pelas sugestões apresentadas à pesquisa. 


\section{Referências}

1. Central Única dos Trabalhadores, Fundação Perseu Abramo, organizadores. CUT 20 anos (1983-2003): resoluções da Conclat e dos congressos e plenárias da CUT. [CD-ROM]. São Paulo: CUT-Editora Fundação Perseu Abramo; 2003.

2. Força Sindical. A Força Sindical e a segurança e a saúde do trabalhador. Saúde em Debate 2002; 26 (62):313-16.

3. Pinheiro JM. O SUS e o desafio neocorporativo. Saúde em Debate 1994; 44:4-8.

4. Faveret P, Oliveira PJ. A universalização excludente: reflexões sobre as tendências do sistema de saúde. Planejamento e Políticas Públicas/Ipea 1990; 3.

5. Mendes EV. Os grandes dilemas do SUS. Salvador: Casa da Qualidade Editora; 2001. (Saúde Coletiva 4, tomo I).

6. Cotta RMM, Muniz JN, Mendes FF, Cotta Filho JS. A crise do SUS e a fuga para o mercado. Rev C S Col 1998; 3(1):94-105.

7. Costa NR. Políticas públicas, direitos e interesses: reforma sanitária e organização sindical no Brasil. Saúde em Debate 1994; 45:23-31.

8. Vianna MLTW. A americanização (perversa) da seguridade social no Brasil: estratégia de bem-estar e políticas públicas. Rio de Janeiro: Revan-Ucam-Iuperj; 1998.

9. Possas C. Saúde e trabalho: a crise da Previdência Social. 2a ed. São Paulo: Hucitec; 1989.

10. Cordeiro HA. As empresas médicas: as transformações capitalistas da prática médica. Rio de Janeiro: Graal; 1984.

11. Oliveira JAA, Teixeira SMF. (IN)Previdência Social: 60 anos de história da Previdência Social. Petrópolis: Vozes; Rio de Janeiro: Abrasco; 1986.

12. Resoluções da Conferência Nacional da Classe Trabalhadora. 21, 22 e 23 de agosto de 1981. In: Central Única dos Trabalhadores, Fundação Perseu Abramo, organizadores. CUT 20 anos (1983-2003): resoluções da Conclat e dos congressos e plenárias da CUT. [CD-ROM] São Paulo: CUT-Editora Fundação Perseu Abramo; 2003.

13. Departamento Intersindical de Estudos e Pesquisa de Saúde e dos Ambientes de Trabalho (Diesat). Tema/ RADIS Fiocruz 1982; 2(1):11-2.

14. Mendes EV. As políticas de saúde no Brasil nos anos 80: a conformação da reforma sanitária e a construção da hegemonia do projeto neoliberal. In: Mendes EV, organizador. Distrito sanitário: processo social de mudança das práticas do sistema único de saúde. São Paulo: Hucitec; 1993. p. 19-91.

15. Banco Mundial. Novo desafio à saúde do adulto. DC, Washington; 1981.

16. Lacaz FAC. Saúde do trabalhador: um estudo sobre as formações discursivas da academia, dos serviços e do movimento sindical [tese]. Campinas: Unicamp; 1996.

17. Lacaz FAC. O Programa de Saúde dos Trabalhadores da Secretaria de Estado da Saúde de São Paulo: A agonia de uma proposta. Saúde em Debate 1992; 36:41-7.

18. Marques VRB, Salermo VL, Gil TB, Rosa SRI, Souza SL, Silvestre MP, et al. O Programa de Saúde do Trabalhador do Município de Campinas. Saúde em Debate $1992 ; 34: 17-24$
19. Departamento Intersindical de Estudos e Pesquisa de Saúde e dos Ambientes de Trabalho (Diesat). Insalubridade: morte lenta no trabalho. São Paulo: Oboré Editorial-Diesat; 1989.

20. Lacaz FAC, Machado JMH, Porto MF. Estudo da situação e tendências da vigilância em saúde do trabalhador no Brasil - Relatório Final do Projeto: 2002. Ago [acessado em 2004 Mai 18; cerca de 115 p.]. Disponível em http://www.opas.org.br/saudedotrabalhador/Arquivos/Sala187.pdf

21. Minayo-Gomez C, Thedim-Costa SMF. A construção do campo da saúde do trabalhador: percurso e dilemas. Cad Saúde Pública 1997; 13(Supl 2):21-32.

22. Lacaz FAC. Saúde do trabalhador: cenários e perspectivas numa conjuntura privatista. 2001 [acessado em 2004 Mai 17; cerca de 21 p.]. Disponível em: http://www.medicina.ufmg.br/spt/seminario_franciscolacaz.rtf.

23. Andreazzi MFS. Teias e tramas: relações público-privado no setor saúde brasileiro dos anos 90 [tese]. Rio de Janeiro: Instituto de Medicina Social/Uerj; 2002.

24. Stotz EN. Movimentos sociais e saúde: notas para uma discussão. Cad Saúde Pública 1994; 10(2):264-8.

25. Boito Jr A. Política neoliberal e sindicalismo no Brasil. São Paulo: Xamã; 1999.

26. Galvão A. Do coletivo ao setor, do setor à empresa: a trajetória do "novo sindicalismo" metalúrgico nos anos 90. In: Rodrigues IJ, organizador. O novo sindicalismo: vinte anos depois. Petrópolis: Vozes; 1999. p. 113-31.

27. Checchia CMA. Assistência médica como um benefício nas empresas: um estudo em organizações de grande porte da cidade de São Paulo [dissertação]. São Paulo: Escola de Administração de Empresas de São Paulo; 1996.

28. Fernandes AESM. Discutindo as demandas sindicais por seguridade social. Revista Universidade e Sociedade. ANDES 1992; 4:23-32.

29. Medici AC. Incentivos governamentais ao setor privado de saúde no Brasil. Revista de Administração 1992; 26(2):79-115.

30. Alves G. Trabalho e sindicalismo no Brasil: um ba lanço crítico da "década neoliberal" (1990-2000) Rev Sociol Polit 2002; (19):71-94.

31. Santos IS. Planos privados de assistência à saúde no mundo do trabalho [dissertação]. Rio de Janeiro: Escola Nacional de Saúde Pública/Fiocruz; 2000.

32. Santos IS. O setor de planos e seguros de saúde e a saúde do trabalhador: que rumo devemos seguir? [Documento elaborado para o Fórum de Saúde Suplementar - ANS]. 2003 Jun-Nov. [acessado em 2004 Mai 14; cerca de 47 p.]. Disponível em: http://www. ans.gov.br/portal/upload/biblioteca/TT_AR_3_ISoa resSantos_SetorPlanosSeguros.pdf).

33. Stotz EM. A fábrica: saúde e servidão burguesa. In: Valla VV, Stotz EN, organizador. Educação, saúde e cidadania. Petrópolis: Vozes; 1994. p. 37-52.

34. Andreazzi MFS. Papel das reformas dos anos 90 na demanda por seguros privados de saúde no Brasil consensos e dissensos. Cad Saúde Col 2003; 11(2): 201-29.

35. Brasil. Secretaria de Política Econômica / Ministério da Fazenda. Gastos do governo central: 2001 e 2002. Brasília: SPE/MF; 2003. 
36. Castro HA, Giannasi F, Novello C. A luta pelo banimento do amianto nas Américas: uma questão de saúde pública. Rev C S Col 2003; 8(4):903-11.

37. Siqueira CE, Castro H, Araújo TM. A globalização dos movimentos sociais: resposta social à globalização corporativa neoliberal. Rev C S Col 2003; 8(4): 847-58.

38. Galvão A. A CUT na encruzilhada: impactos do neoliberalismo sobre o movimento sindical combativo. Campinas. Idéias 2002; 9(1):105-54.

39. Central Única dos Trabalhadores. 6o Congresso Nacional da Central Única dos Trabalhadores: resolu ções e registros. São Paulo: CUT; 1997.

40. Fórum de Saúde Suplementar - 1a etapa. Relatório Geral. ANS; 2003 Jun [acessado em 2004 Set 23; cerca de 93 p.]. Disponível em:http://www.ans.gov.br/ portal/upload/forum_saude/forum_imprensa/forum_etapa1/RelatorioGeral.pdf

41. Central Única dos Trabalhadores. [Documento elaborado para o Fórum de Saúde Suplementar - ANS] Brasília: 2003 Jun [acessado em 2004 Mai 14; 1 p Disponível em http://www.ans.gov.br/portal/upload/ forum_saude/Forum_temas/CUT.pdf.

42. Central Única dos Trabalhadores. Política da CUT para a saúde no trabalho e o meio ambiente. Relatório do Seminário de Saúde, Trabalho e Meio Ambiente. São Paulo: 1994 Ago. [Mimeo].
43. Pina JA. Sindicalismo e saúde no Brasil: a relação Sistema Único de Saúde (SUS) e os planos privados de saúde na assistência à saúde dos trabalhadores [dissertação]. Rio de Janeiro: Escola Nacional de Saúde Pública Sérgio Arouca/Fiocruz; 2005.

44. Oliveira SGA. Convênio-Empresa: balanço crítico uma relação de poder entre empregador/empregado em torno da assistência médica [dissertação]. São Paulo: PUC-São Paulo; 1991.

45. Chahad JPZ. Tendências recentes no mercado de trabalho: pesquisa de emprego e desemprego. São Paulo Perspec 2003; 17(3-4):205-17

46. Instituto Brasileiro de Defesa do Consumidor. O SUS pode ser seu melhor plano de saúde. São Paulo: Idec 2003 [acessado 2006 fev 10; cerca de 63 p.]. Disponível em http://www.idec.org.br/arquivos/cartilha_SUS.pdf.

47. Zarpelon SR. ONGs, movimento sindical e o novo socialismo utópico. Campinas. Idéias 2002; 9(1):203-44.

48. Stotz EN. Trabalhadores, direito à saúde e ordem social no Brasil. São Paulo Perspec 2003; 17(1):25-33.

Artigo apresentado em 27/02/2006

Aprovado em 31/03/2006

Versão final apresentada em 17/04/2006 